\title{
EVALUATION OF THE EFFECT OF DIFFERENT CONCENTRATIONS OF ALOE VERA ON INFLAMMATION AND REEPITHELIALIZATION IN DIABETIC ULCERS IN A RAT MODEL
}

\author{
YUNITA SARI ${ }^{1 *}$, IWAN PURNAWAN ${ }^{1}$, EMAN SUTRISNA $^{2}$, DHADHANG WAHYU KURNIAWAN ${ }^{3}$, NASRUDDIN $^{4}$
}

${ }^{1}$ Department of Nursing, Jenderal Soedirman University, Indonesia. ${ }^{2}$ Department of Pharmacology, Jenderal Soedirman University, Indonesia. ${ }^{3}$ Department of Pharmaceutics, Jenderal Soedirman University, Indonesia. ${ }^{4}$ Department of Medical Laboratory Science Universitas Muhammadiyah Semarang, Indonesia. Email: sasa.yunita@gmail.com/yunita-tky@umin.ac.jp

Received: 01 January 2018, Revised and Accepted: 29 August 2018

ABSTRACT

Objective: The objective of this research was to evaluate the effect of different concentrations of Aloe vera (AV) on inflammation of diabetic ulcers in a rat model.

Methods: The induction of diabetes was conducted by injection of alloxan monohydrate. This study involved four groups, including $0 \%$, $10 \%$, $30 \%$, and inner leaf AV (ILAV) gel groups. Necrotic tissue, wound size, inflammation, and reepithelialization were evaluated. Wound tissue was collected on days 4 and 8 . Histological analysis was performed by hematoxylin and eosin staining. Differences in the intensity of inflammation were analyzed using Kruskal-Wallis test followed by Mann-Whitney U-test.

Results: On day 13, wounds in gels containing AV were almost completely healed, whereas wounds in the $0 \%$ gel group (control) were still covered with necrotic tissue. On day 3, the intensity of inflammation in the $30 \%$ and ILAV groups was significantly less when compared to the $10 \%$ and control groups. On day 8, inflammation was less significant in the 10\%, 30\%, and ILAV groups when compared with the control group. Moreover, the intensity of inflammation in the $30 \%$ and ILAV groups was significantly less compared to the $10 \%$ group. In addition, reepithelialization was more advanced in the $10 \%$ and $30 \%$ ILAV groups compared with the control group, and reepithelialization was most advanced in the $30 \%$ and ILAV groups.

Conclusion: Our study indicated that gels containing AV reduced inflammation and improved reepithelialization of diabetic ulcers in a rat model. Therefore, it is highly recommended for clinicians to use AV gels for topical treatment of diabetic ulcers.

Keywords: Aloe vera, Diabetic ulcer, Inflammation, Rat, Reepithelialization.

(C) 2018 The Authors. Published by Innovare Academic Sciences Pvt Ltd. This is an open access article under the CC BY license (http://creativecommons. org/licenses/by/4. 0/) DOI: http://dx.doi.org/10.22159/ajpcr.2018.v11s3.30024

\section{INTRODUCTION}

Diabetes mellitus (DM) has become a serious health problem, worldwide, because it can significantly increase health-care costs, reduce the quality of life, and cause mortality. It has been reported that more than 347 million people suffer from DM globally [1]. This number is likely to be doubled by 2030 . In a previous study, it was reported that almost $80 \%$ of mortalities due to DM occur in low- and middle-income countries [1].

One of the complications of DM is diabetic ulcer. In a previous study, it has been reported that up to 26, 1 million patients with DM suffer from diabetic foot ulcers [2]. Among all amputations in diabetic patients, $85 \%$ were preceded by foot ulcers. A previous study showed that more than $80 \%$ of amputations are due to foot ulcers $[3,4]$ and that the mortality rate due to diabetic foot ulcers is quite high. It has been reported that the 5-year mortality rate due to diabetic foot ulcers was as high as $74 \%$ [5].

In general, wound care technologies are used to accelerate wound healing of diabetic foot ulcers in patients [6,7]. However, such technologies are usually not present in developing or low-income country, such as Indonesia. Therefore, natural products are often used for wound treatment. In Indonesia, the natural product that is commonly used to treat diabetic foot ulcers is AV.

In previous studies, it was reported that AV had several pharmacological activities, including hypoglycemic effects, anti-inflammatory, antibacterial, antifungal, and antiarthritis. Due to its properties, AV has been used for the treatment of wounds [8]. In a previous study, it was reported that AV accelerated the healing of burn wounds and acute wounds [9]. Moreover, it has been shown that AV improved wound healing in diabetic rats by promoting wound healing in the proliferating phase, including fibroblast proliferation, myofibroblast differentiation, and extracellular matrix formation [10]. Although it has been shown that $\mathrm{AV}$ accelerated wound healing during the proliferation phase, the roles of $\mathrm{AV}$ in the inflammation phase and re-epithelialization phase are still unclear. In a previous study by Chitra (1998) and Daburkar (2014), tissue was investigated on days 3 and 13; however, their study focused on the effect of $\mathrm{AV}$ on promoting tissue proliferation; however, the effect of $A V$ on inflammation was not investigated [11,12]. Moreover, the concentration of $\mathrm{AV}$ that can reduce inflammation and improve reepithelialization is also still unclear. Therefore, the purpose of our study was to evaluate the effect of different concentrations of AV on inflammation and reepithelialization of diabetic ulcers in a rat model.

\section{METHODS}

\section{Chemicals}

Chemicals were used in this study, including sodium alginate, and methylparaben was from Bratachem, Indonesia. Alloxan monohydrate and ketamine hydrochloride were purchased from Sigma-Aldrich Co (St. Louis, MO, USA). All other compounds used were of analytical grade.

\section{Preparation of gels}

The identity of AV was confirmed by the Department of Pharmaceuticals, Jenderal Soedirman University, Indonesia. The surface of the leaves was cleaned with ethanol to remove debris or dirt. The leaves were separated from the gel of the plant using sterilized surgical blades. Next, AV was chopped into small pieces, air-dried, and grinded into powder. 
AV powder was extracted with $95 \%$ ethanol at $90^{\circ} \mathrm{C}$ for 5 days and evaporated into concentrated extract using a distillation set.

Preparation of AV gels was according to the methods described in a previous study [13]. Briefly, sodium alginate was mixed with ethanol and distilled water and then allowed to stand for 10 min until expanded. Methylparaben was dissolved in glycerin. AV extract was then put into the basic mixture, stirred until homogeneous, and a gel mass had formed. A total of 100 of gel was applied to the wound using a micropipette.

\section{Animals}

Male Wistar rats weighing 180-200 g (age 12-14 weeks) were used in this study. Rats were purchased from the Department of Pharmacy, Muhammadiyah University (Purwokerto, Indonesia). Rats were given food and water ad libitum. The animal protocol was approved by the Ethical Committee of the University of Jenderal Soedirman (Purwokerto, Indonesia).

\section{Induction of diabetes and wounding procedure}

Rats were acclimated for 1 week before induction of diabetes. To establish hyperglycemic rats, rats were injected with alloxan hydrochloride ( $90 \mathrm{mg} / \mathrm{Kg}$ body weight). To confirm that rats had become hyperglycemic, blood was collected from the tail vein and glucose levels were assessed. Rats were included in experiments when blood glucose levels reached $275 \mathrm{Mg} / \mathrm{dl}$.

Rats were shaved 1 day before wounding. On the wounding day and before the wounding procedure, rats were anesthetized by ketamine hydrochloride ( $40 \mathrm{mg} / \mathrm{kg}$ body weight). The wounding procedure was performed based on our previous study [14]. Wounds with a diameter of $1 \mathrm{~cm}$ were made on the dorsum of the rats, and the rats were divided into four groups: $0 \%$ gel group, $10 \%$ gel group, $30 \%$ gel group, and inner leaf AV (ILAV) group. The group of $0 \%$ means was injected with a gel that did not contain $\mathrm{AV}$, and it only contained the base gel and acted as a control group. Rats were anesthetized through intraperitoneal injection of ketamine hydrochloride. Wounds with a diameter of $1 \mathrm{~cm}$ were made on the back of rat

Wounds were cleansed every day with a normal saline solution. After cleansing, the gel $(100 \mu \mathrm{l})$ was applied to the wound. After the application of gel, wounds were covered with transparent film dressing.

\section{Histological procedure}

Animals were sacrificed on post-wounding days 4 and 8 and harvested on the same day. Tissues were fixed in $10 \%$ formaldehyde, dehydrated through a graded series of alcohol and xylene, embedded in paraffin, and cut into $4-\mathrm{mm}$ thick sections. Sections were then stained with hematoxylin-eosin (HE) staining and observed under a light microscope at $\times 40$ magnification. Tissue examination was performed according to a previous method [15].

\section{Statistical analysis}

Statistical analyses were conducted by SPSS software (SPSS version 21 for Windows, SPSS Inc., Chicago, IL, USA). To compare the intensity of inflammation between groups, Kruskal-Wallis test followed by MannWhitney test was used. $\mathrm{p}<0.05$ was considered statistically significant.

\section{RESULTS}

\section{Macroscopic findings}

The macroscopic findings are presented in Fig. 1. The appearance of the wounds on the day 0 was similar for all groups. From day 1 to day 9 , the wounds in all groups were covered with a thin layer of necrotic tissue. On day 13, wounds in the all groups containing AV were almost completely healed, whereas wounds in the control group were still covered with necrotic tissue.

\section{HE staining}

The histological findings in the epidermis dan dermis layer on day 4 are presented in Fig. 2. Fig. 2 shows that the intensity of inflammation was the highest in the control group when compared with the other groups. Moreover, when comparing the groups which were given $\mathrm{AV}$, wounds treated with $10 \%$ AV showed a higher intensity of inflammation when compared with the $30 \%$ and ILAV groups. The intensity of inflammation was similar between the $30 \%$ and ILAV groups. Differences in the intensity of polymorphonuclear neutrophils (PMNs) are shown in Table 1. Inflammation was significantly less in the $30 \%$ and ILAV groups when compared with the $10 \%$ and control groups $(\mathrm{p}=0.026,30 \%$ vs. $10 \%$ group, $\mathrm{p}=0.029,30 \%$ vs. control group, $\mathrm{p}=0.008$, ILAV vs. control, $\mathrm{p}=0.029$, ILAV vs. $10 \%$ group). No significant differences were found between the $10 \%$ group and the control group $(\mathrm{p}=0.788)$. The intensity of fibroblasts in the $30 \%$ and ILAV groups was higher when compared with the control and $10 \%$ group.

Histological findings of the epidermis dan dermis layer on day 8 as well as the appearance of reepithelialization are presented in Fig. 3, which showed that the intensity of inflammation in $10 \%, 30 \%$, and ILAV was less when compared with the control group ( $0 \%$ group). When the inflammation among $10 \%, 30 \%$, and ILAV was compared, the intensity of inflammation was less in the $30 \%$ and ILAV compared with $10 \%$

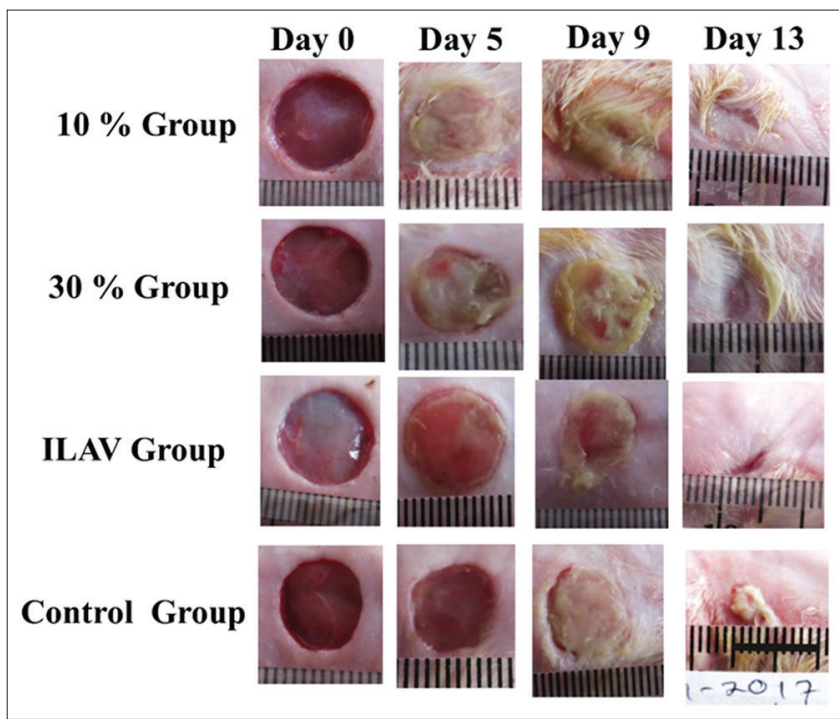

Fig. 1: Macroscopic findings of wounds treated with $10 \%$ gel (first row), $30 \%$ (second row), inner leaf Aloe Vera (ILAV) (ILAV; third row), and $0 \%$ group (fourth row) (bar $=1 \mathrm{~cm}$ )

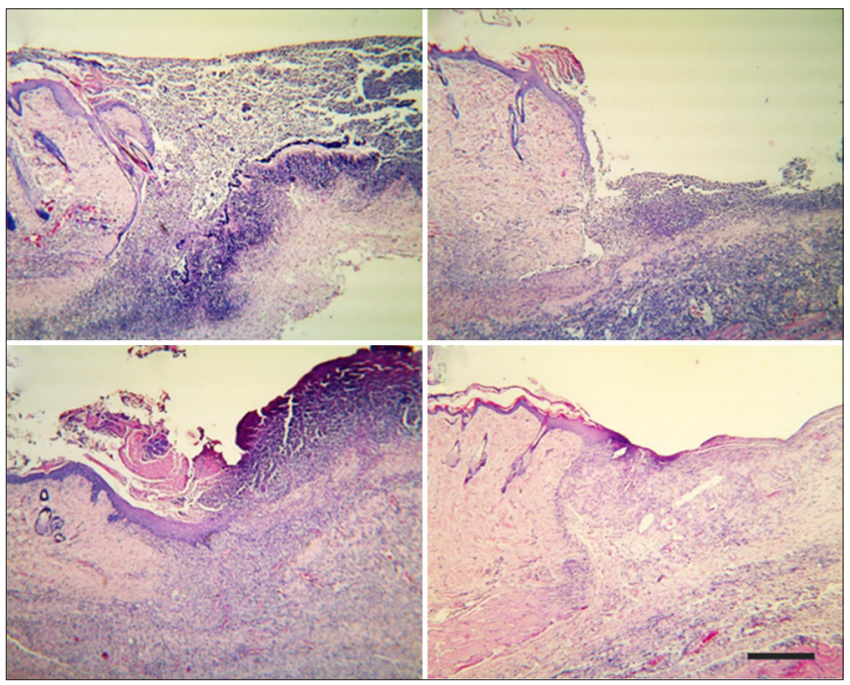

Fig. 2: Hematoxylin and eosin staining in the $0 \%$ (control group), $10 \%, 30 \%$, and inner leaf Aloe Vera groups (bar= $500 \mu \mathrm{m}$ ) 


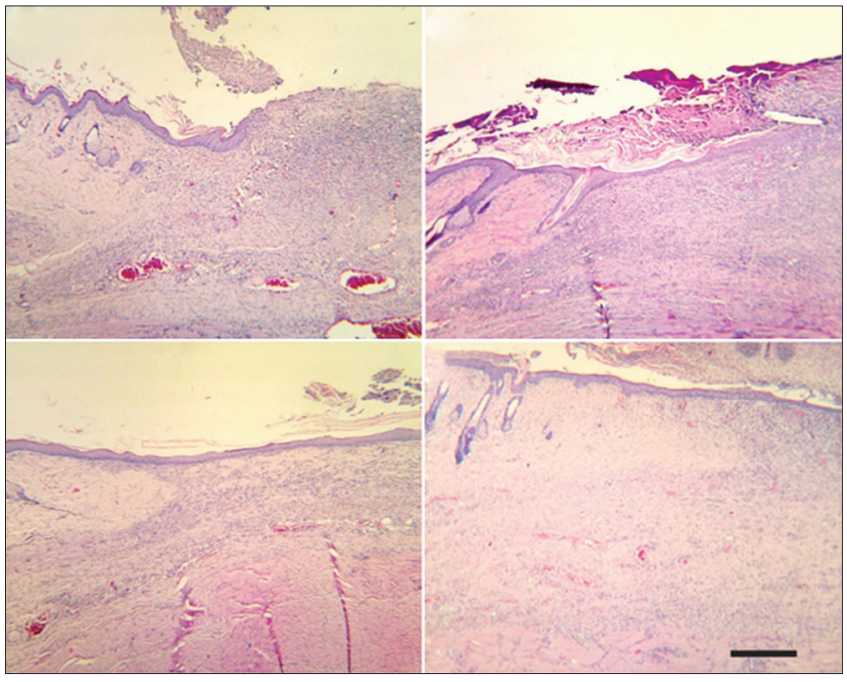

Fig. 3: Wound reepithelialization in $0 \%, 10 \%, 30 \%$, and inner leaf Aloe Vera groups $(\mathrm{bar}=\mathbf{5 0 0} \boldsymbol{\mu m})$

Table 1: Intensity of inflammation

\begin{tabular}{lll}
\hline Groups & PMNs on day 4 & PMNs on Day 8 \\
\hline Aloe vera $10 \%$ & 3.5 & $2.5^{*}$ \\
Aloe vera $30 \%$ & $2^{*+}$ & $1.5^{*+}$ \\
ILAV & $2^{* *+}$ & $1.5^{*+}$ \\
Aloe vera $0 \%$ (control) & 4 & 3.5 \\
\hline
\end{tabular}

Values indicated median score. Rating scale: $0=$ absent, $1=$ occasional,

2 =moderate, $3=$ abundant, $4=$ very abundant. ${ }^{*}=\mathrm{P}<0.05$ (compared with control group), $\uparrow \mathrm{p}<0.05$ (compared with $10 \%$ group). PMNs: Polymorphonuclear neutrophils, ILAV: inner leaf Aloe Vera

group. The intensity of inflammation in $30 \% \mathrm{AV}$ and ILAV was similar. The difference of the intensity of PMNs is shown in Table 1 . The intensity of PMNs in $30 \% \mathrm{AV}$ and ILAV was significantly less when compared with the control and $10 \%$ group. Moreover, the intensity of the inflammation in the $10 \%$ group was significantly less when compared to the control group ( $\mathrm{p}=0.03,30 \%$ vs. $10 \%$ group, $\mathrm{p}=0.01,30 \%$ vs. the control group; $\mathrm{p}=0.03$, ILAV vs. control, and $\mathrm{p}=0.08$, ILAV vs. $10 \%$ group). On the day 8 , the intensity of inflammation in the $10 \%$ group was significantly less when compared with the control group $(\mathrm{p}=0.03)$. In addition, the intensity of fibroblasts in the $30 \%$ group and the ILAV group was higher compared with that of the control and the $10 \%$ group.

Fig. 3 shows that reepithelialization was advanced in gels containing AV compared with the control group. The most advanced reepithelialization was observed in the $30 \%$ group and ILAV groups.

\section{DISCUSSION}

To the best of our knowledge, this is the first study to investigate the effect of $\mathrm{AV}$ on reducing inflammation on diabetic ulcers in a rat model. Previous studies only focused on the effect of $\mathrm{AV}$ in the proliferation phase in diabetic ulcers. Chitra et al. (1998) investigated the tissue condition on day 3 (inflammation phase); however, their study only assessed the effects of AV on granulation tissue [11]. In another study by Daburkar et al. (2014), the effects of AV on diabetic wounds were investigated; however, this study also focused on the formation of collagen formation in the wound (proliferation phase) [12].

In general, wound healing of diabetic ulcers is delayed. The delayed wound healing in diabetic ulcers is in part due to the prolonged inflammation phase, delayed granulation tissue formation, and delayed reepithelialization $[16,17]$. Therefore, to accelerate wound healing of diabetic ulcers, topical therapy that can reduce inflammation, improve granulation tissue, and accelerate reepithelialization is required.
AV has shown beneficial effects in traditional medicinal practice and cosmetic purposes [15]. In a previous study, it was revealed that $\mathrm{AV}$ has pharmacological effect effects, including anti-inflammatory, antiarthritis, antibacterial, antifungal, and hypoglycemic effects [15]. Moreover, the previous studies have shown that AV could be used to treat hepatoxicity and sepsis [18]. Related with wound healing, AV has been known to accelerate wound healing of acute wounds and burn wounds [9].

In this study, the intensity of inflammation of groups treated with $\mathrm{AV}$ correlated with the intensity of PMNs in the $10 \%, 30 \%$, and ILAV groups when compared with the group that did not contain AV. In our study, groups treated with AV $10 \%$ and $30 \%$ showed a reduction in inflammation, with better results occurring in the $30 \%$ group. The ability of AV 30\% to reduce inflammation may be due to the content of anthraquinone in AV. In a previous study, it was shown that the ethanol extract of AV still contained anthraquinone, which is known to function as an anti-inflammation agent [19]. This compound may mediate the beneficial effects of $\mathrm{AV}$, such as reducing inflammation in diabetic ulcers. Based on the study of inflammation of the peritoneal cavity in normal rats, the mechanism of AV to reduce inflammation may relate to the inhibitory activity of the arachidonic acid pathway through cyclooxygenase inhibition, rather than a direct effect on lipooxygenase activity [20]. Additional studies will be needed to confirm the mechanism of reducing inflammation by $\mathrm{AV}$ in diabetic ulcers. In this study, the level of inflammation on day 8 between AV $30 \%$ and ILAV groups is similar. Why AV $30 \%$ and ILAV on day 8 demonstrated similar results in reducinginflammation also needs to be futher elucidated. The content of anthraquinone may be less when compared with ILAV, but the level of inflammation in the $30 \%$ group was similar to those of rats in ILAV groups.

In this study, we showed that reepithelialization was improved in gels containing AV when compared with gels that did not contain AV. The delay of reepithelialization in diabetic ulcers usually occurs due to the increase of MMP-9. MMP-9 is an enzyme that can degrade collagen [20]. Previous in vitro studies revealed that AV reduced levels of MMP-9 [20]. The reduction of MMP-9 may be the mechanism involved. Further studies are needed to elucidate the mechanism of action

\section{CONCLUSION}

In this study, we evaluated the effect of $\mathrm{AV}$ on reducing inflammation and improving reepithelialization of diabetic ulcers in a rat model. The results indicated that wounds treated with $10 \%, 30 \%$, and ILAV showed reduced inflammation and improved reepithelialization of the wound when compared to wounds treated with gels that did not contain AV. The reduction in inflammation and improvement of reepithelialization in the wound on the day 8 treated with $30 \%$ of $A V$ showed similar results when compared to wounds treated with ILAV.

\section{CONFLICTS OF INTEREST}

All authors have none to declare.

\section{REFERENCES}

1. World Health Organization (WHO). Fact Sheet No. 312; WHO Media Centre 2013. c2017. Available from http://www.who.int/mediacentre/ factsheets/fs312/en/. [Last cited on 2017 Nov 10].

2. Armstrong DG, Boulton AJ, Bus SA. Diabetic Foot Ulcers and Their Recurrence. N Engl J Med 2017;376:2367-75.

3. Pecoraro RE, Reiber GE, Burgess EM. Pathways to diabetic limb amputation. Basis for prevention. Diabetes Care 1990;13:513-21.

4. American Diabetes Association. Consensus development conference on diabetic foot Wound Care. Diabetes Care 1999;22:1354-60

5. Moulik PK, Mtonga R, Gill GV. Amputation and mortality in new-onset diabetic foot ulcers stratefied by etiology. Diabetes Care 2003;26:491-4.

6. Kaya A, Aydin F, Altay T, Karapinar L, Ozturk H, Karakuz C. Can major amputation rates be decreased in diabetic foot ulcers with hyperbaric oxygen therapy? Int Orthop 2009;33:441-6.

7. Nain PS, Sanjeev K, Uppal SK, Garg R, Bajaj K, Garg S. Role of 
negative pressure wound therapy in healing of diabetic foot ulcers. J Surg Tech Case Rep 2011;3:17-22.

8. Eshun K, He Q. Aloe vera: A valuable ingredient for the food, pharmaceutical and cosmetic industries - a review. Crit Rev Food Sci Nutr 2004;44:91-6.

9. Akhoondinasab MR, Akhoondinasab M, Saberi M. Comparison of healing effect of Aloe vera extract and silver sulfadiazine in burn injuries in experimental rat model. World J Plast Surg 2014;3:29-34

10. Sánchez-Elsner T, Botella LM, Velasco B, Corbí A, Attisano L, Bernabéu C. Synergistic cooperation between hypoxia and transforming growth factor- $\beta$ pathways on human vascular endothelial growth factor gene expression. J Biol Chem 2001;276:38527-35.

11. Chithra P, Sajithlal GB, Chandrakasan G. Influence of Aloe vera on the healing of dermal wounds in diabetic rats. J Ethnopharmacol 1998;59:195-201.

12. Daburkar M, Lohar V, Rathore A, Bhutada P, Tangadpaliwar S. An in vivo and in vitro investigation of the effect of Aloe vera gel ethanolic extract using animal model with diabetic foot ulcer. J Pharm Bioallied Sci 2014;6:205-12.

13. Widia W. Formulasi Sediaan gel Ekstrak Etanol Daun Lidah Buaya (Aloe Vera) Sebagai anti Jerawat Dengan Basis Sodium Alginate dan Aktivitas Anti Bakterinya Terhadap Staphylococcus epidermidis. Unpublished; 2015.
14. Sari Y, Saryono S, Purnawan I, Hartono H. Modification of breast pump as a negative pressure wound therapy for accelerating wound healing of diabetic ulcer. J Ners 2014;10. Available from: http://www.ejournal. unair.ac.id/index.php/JNERS/article/view/2037/1499. [Last accessed on 2018 Dec 01]

15. Wright JB, Lam K, Buret AG, Olson ME, Burrell RE. Early healing events in a porcine model of contaminated wounds: Effects of nanocrystalline silver on matrix metalloproteinases, cell apoptosis, and healing. Wound Repair Regen 2002;10:141-51.

16. McLennan S, Yue DK, Twigg SM. Molecular aspects of wound healing in diabetes. Primary Intention 2006;14:8-13.

17. Soneja A, Drews M, Malinski T. Role of nitric oxide, nitroxidative and oxidative stress in wound healing-review. Pharmacol Rep 2005;57:108-19.

18. Liu PH, Chen D, Jie S. Chemical constituents, biological activity and agricultural cultivation of Aloe vera. Asian J Chem 2013;25:6477-85.

19. Fizquez B, Avila G, Segura LD, Escalante B. Antiinflammatory activity of extracts from Aloe vera gel. J Ethnopharmacol 1996;55:69-75.

20. Kudalkar MD, Nayak A, Bhat KS, Nayak RN. Effect of Azadirachta indica (Neem) and Aloe vera as compared to subantimicrobial dose doxycycline on matrix metalloproteinases (MMP)-2 and MMP-9: An in-vitro study. Ayu 2014;35:85-9. 